\title{
Emerging Problems in Knowledge Sharing and the Three New Ethics of Knowledge Transfer
}

\author{
Mikhail Koulikov* \\ New York Law Institute \\ 120 Broadway, Suite 932, New York, NY 10271, USA \\ E-mail: mkoulikov@nyli.org \\ *Corresponding author
}

\begin{abstract}
Topics related to knowledge management and knowledge sharing have received extensive attention in the recent literature of management and information science. Much of the discussion has focused on how these processes take place - and frequently fail to take place - in formal business, corporate and organizational settings. Knowledge sharing, however, occurs along the entire spectrum of human activity. Often, information and knowledge are shared in ways that appear unregulated and even outright subversive. This paper surveys many of the recent critiques of formal mechanisms of knowledge sharing. It identifies a set of methods, structures and ethics of "informal" and unauthorized transfer of information, and suggests that these can offer valuable lessons for the further development of the study of knowledge sharing methods, practices and behaviors in all types of settings.
\end{abstract}

Keywords: Knowledge Sharing; Hacker Ethic; Participatory Culture; Proselytization Commons

Biographical notes: Mikhail Koulikov is a Reference/Research Librarian at the New York Law Institute. His academic interests include social informatics and social epistemology, interdisciplinary scholarly communication, comparative bibliometrics, and emerging issues in law librarianship and legal information management. His research has been published in the Law Library Journal, Transformative Works and Cultures, and several professional magazines/newsletters. Mr. Koulikov holds an undergraduate degree in international affairs from the George Washington University, and a master's in library science from Indiana University, Bloomington.

\section{Introduction}

On April 29, 2008, the video game Grand Theft Auto IV was released to stores throughout the U.S. By August, over ten million copies, priced at \$59.99 each, had been sold (Take-Two Interactive Software, 2008), making it one of the year's most successful entertainment products in any medium. And yet, several days before its launch date, illegal or unauthorized copies of the game were already available for free download online. Much of the popular conversation about "software piracy" brings to mind images of stealing for profit. Yet in reality, activities of this type frequently involve individuals who commit time, effort and resources and take clear risks to, essentially, share information (and knowledge) without any clear benefit to them. Beyond the specific technical and legal questions raised by these activities lies the broader issue of how 
individuals interact with knowledge, and more specifically, what are the reasons and the specific factors that influence or affect the decision to share knowledge and the actual process of knowledge sharing. From this, then, rises the intriguing possibility that the kind of knowledge sharing that goes on daily in informal, unauthorized, and outright illegal communities of the type just described can be used to answer some of the questions about the nature of the knowledge sharing process in general. This study examines not just the processes of informal, unauthorized knowledge sharing, but the ethical considerations that underlie these processes. It identifies "ethics of knowledge transfer", each of which is distinguished by a particular understanding of the role that information and knowledge play in human activity. These ethical considerations, in turn, can contribute to a basic framework for understanding how knowledge sharing can occur in any context, whether formal or informal, commercial or non-commercial, authorized or unauthorized.

\section{Knowledge and Knowledge Sharing}

The exchange of information is, essentially, the interaction that is at the root of information science. However this process is conceptualized, as Barrett and Konsynski (1982) note, "the interchange of information, whether subtle or concrete, forms the basis of all organizational activity." The data-information-knowledge-wisdom spectrum, and the particular ways in which those terms are defined, is of course key to thinking about this process, and before any real discussion of knowledge sharing can be started, some time must be taken to think about what exactly is meant by the term 'knowledge.' Churchman (1971) connects knowledge with the "capacity to act." Davenport, De Long, and Beers (1998) argue that knowledge is a "high-value form of information." Both imply that it is the effect of transformation of a particular type applied to something that already exists.

\subsection{What is knowledge sharing?}

As a concept, "knowledge sharing" is by now well-established in the management and information science literature. Specific definitions, however, are surprisingly infrequent. A typically circular approach is Bartol and Srivastava's (2002) - "We define knowledge sharing as individuals sharing organizationally relevant information." Bock and Kim (2002) call the process a "specialized form of economic and cultural exchange." More broadly, Ives, Torrey and Gordon (2000) discuss knowledge sharing as a "critical human behavior", a function, essentially, of being human. Helmstadter (2003) comes much closer to encompassing what knowledge sharing actually is, rather than what the process entails. Knowledge sharing, he writes, consists of "voluntary interactions between human actors through a framework of shared institutions, including ethical norms, behavioral regularities, and so on. The subject matter of the interactions between the participating actors is knowledge." Such a definition emphasizes the idea that knowledge sharing is a form of communication that can also be thought of as a transfer of commodities and thus subject to economic principles. Knowledge is a commodity; knowledge has - or can have - specific value. Clearly, the importance of sharing knowledge, both in theory and in specific instances, has been accepted as a given. However, for all of the discussions of what is meant by knowledge sharing, relatively little thought has been given to exactly why it occurs, and whether (or how) knowledge sharing can be induced or made to actually take place. 


\subsection{Knowledge sharing models}

Much of the recent thinking about the structure and process of knowledge sharing builds on Takeuchi and Nonaka's 1995 model of the circular, ongoing relationship between tacit and explicit knowledge. In this model, there is no point at which either the generation or the sharing of knowledge stops or can be made to stop, and in fact, the knowledge process is continuously transformative. "New" knowledge, in their view, grows on and modifies existing knowledge. Yet neither the original model nor the ways in which it has been applied and interpreted give much thought to what, if anything, drives the process, what sets it in motion, what the goal of the process is, or even what kinds of barriers can appear along the cycle. As Schultze and Leidner caution (2002), thinking about knowledge and knowledge sharing has frequently been uncritical and essentially normative, with a tendency to in fact regress and ignore the spectrum. Knowledge, they remind, is a lot more than simply a critical mass of accumulated data that can exist outside the individual, be stored, manipulated, and transferred simply by the virtue of the existence of a particular transfer mechanism. In fact, dialogic, interpretive, and critical discourses all have a place in the discussion of knowledge management and knowledge sharing. Thinking about the reasons for knowledge to exist and for knowledge sharing to take place is crucial to establishing an environment where the process will indeed occur, and to fostering the conditions for effective knowledge sharing. Ignoring this can be seen in typical uses of the term 'knowledge sharing' in the context of describing software platforms and systems ("Xerox offers new knowledge sharing solutions", 1999; Stoddard, 2001) that presumably, once in place, would be all that is needed for knowledge to be created and for knowledge sharing to take place.

\subsection{The models' limitations}

Of course, this is rarely the case - as knowledge theorists have recognized all along, and as those who actually try to implement "knowledge sharing solutions" are finding out in practice. Brazelton and Gorry (2003) demonstrate the kinds of questions that are bound to rise up before the practitioner who is about to throw his or her lot in with a technological solution to what, essentially, is an issue that is far more than merely technological. "If we build it, will they come?", they ask. Moreover, as with all technologies, intended or expected uses are one thing; the actual ways the technologies in question are used is another entirely. Economides (2008), in his discussion of the tools and modes used by learners and teachers, highlights the importance of "culture-aware learning". Olaniran (2009) expands on this in the context of a discussion of international dimensions of elearning. Pre-existing "cultural values and societal norms," such as oral traditions, learning styles, and the culturally expected uses of particular technologies all have a major influence on whether any technology for knowledge transfer is welcomed and adopted.

\section{Why knowledge sharing fails - and how, and when?}

In this context, what Davenport (1996) argues is particularly important to keep in mind. Acquiring, much less sharing, knowledge is an "unnatural act" that is at the very least time-consuming, and, quite possibly, wrought with actual dangers to whoever attempts to engage in it. The principles of sharing are taught at an early age, and the practice is then expected in many settings, but at a certain point, particularly in institutional and corporate environments, it is often actually discouraged (Ives, Torrey and Gordon, 2000). Knowledge can be thought of as a noun, or in any case, there is a relationship between 
knowledge and specific objects, but "sharing" is an action, and so, it possesses "verb-like qualities" (Smoliar, 2007). This is conceptually similar to Dervin's view that information is inherently a verb or action, rather than a fixed construct or object, and that "knowledge versus information are system distinctions of no meaning to lived experience and movement through space" (Savolainen, 2006).

A large proportion of all knowledge management and knowledge sharing initiatives that are launched by organizations fail (Storey \& Barnett, 2000). Understanding why they do, and why knowledge sharing fails to occur when it is expected to, is a crucial step in figuring out how to facilitate the knowledge sharing process. A particularly illustrative example of this failure is Currie and Kerrin's (2004), which finds that frequently, the only result of a blind and basically thoughtless implementation of "a knowledge sharing solution" is an actual "hardening" of existing practices, and an increase in resistance to even the idea of knowledge sharing.

\subsection{The dilemmas of knowledge sharing}

An important addition to the recent literature on the problems of knowledge sharing is the 2002 paper by Cabrera and Cabrera, which specifically addresses the "dilemmas" that the practice of knowledge sharing presents. One of these is the interplay between the public good, which is presumably maximized by sharing knowledge, and individual payoffs, which may not be. In addition, since the benefits of knowledge sharing are distributed to the group, rather than based directly on individual contributions, there may be a strong temptation to "free-ride" - in essence, to wait for someone else to share, and then reap the benefits. Any system that supports or facilitates knowledge sharing must be able to address and overcome these two "social" and "public good" dilemmas. Of course, knowledge sharing also implies very real costs. At the most basic level, there is the opportunity cost of the activity, where the time spent on it has to be evaluated against other tasks that are possibly more pressing or more immediately beneficial. More specifically, a comprehensive study by Riege (2005) identifies over thirty specific factors that serve as barriers to the free flow of information/knowledge, particularly in organizations. Most of these can variously be characterized as either individual (such as the desire to take ownership of intellectual property and secure just compensation for one's contributions) or organizational (for example, a high level of internal competition, where the creation of knowledge is quantified and used as a benchmarking or rating tool). Riege also identifies several relevant technological factors, but these often have to do with being unfamiliar with the limits of technology, or, expecting technological solutions to resolve situations that are actually caused by either individual or organizational factors.

\subsection{Social and economic dimensions}

So, what are the actual drivers of knowledge sharing, and how can they be harnessed and repurposed or directed to achieve specific goals? In comparison to the significant literature that exists on information-seeking, the "giving" part of the information exchange process has been discussed far less often. Rioux (2005) introduces several important concepts to keep in mind when thinking about how knowledge is shared. The term 'transaction' may be used, but the process is as much social as it is economic, and knowledge sharing is, at its heart, a form of gift-giving. It is also reflexive, in that individuals may determine specifically what kind of knowledge to share, and when, after finding it "useful and desirable" for their own purposes. As Hart (2002) argues, another important consideration has to do with individual approaches to, and understandings of, the idea of "ownership" and of the rights (and perhaps responsibilities) that "ownership" 
implies. Whether one views it from a Kantian "first occupancy" standpoint, Lockean concepts of labor theory, Bentham and Mill's ideas of utility, Hegelian personality theory, or the comparatively more recent libertarian approaches of Rawls and Nozick will have particular implications to how an individual generates knowledge, what purposes he or she has in doing so, the actual goal of knowledge generation, and the possibility that this knowledge will be shared or transferred more or less freely, and despite any possible hindrances.

\subsection{Philosophies}

Knowledge sharing is a practice, but it is supported by - and builds upon - certain philosophies. Thus Chua (2003) argues that knowledge sharing has to be discussed with the idea of contexts in mind. In addition, these practices are highly sensitive to participant identities; individuals will share knowledge if and when they can be assured that others in their milieu will do the same, thus overcoming the "public good" dilemma discussed earlier. An important implication of this proposition is that while knowledge sharing is not natural, a knowledge sharing culture is possible, feasible, and can be cultivated or fostered by means that are not technological, but, rather, social or even grounded in a particular ideology. This assertion, especially the emphasis on contexts, is also discussed by Augier, Shariq, and Vendelo (2001). While contexts are inherently based on individual experiences, these experiences may be sufficiently similar for contexts to also have a number of similarities. This, in turn, gives support to Rioux's idea of the "reflexivity of knowledge sharing." Working from this, an understanding of the commonality of contexts may be used to, as Kankanhalli, Tan, and Wei (2005) suggest, bridge the gap between the perceived costs and the expected benefits of knowledge sharing. The next logical development in this kind of thinking implies that if one shares knowledge in a particular situation where another person has a stated or perceived need for it, he or she may also reasonably expect to find a repeat situation where they will in fact be needing shared knowledge.

Borghi's (2005) contribution to knowledge sharing theory consists of connecting this discussion to its basically Kantian roots. Knowledge, he argues, is based in cognition, and is essentially dualistic. The purpose of scholastic knowledge is to achieve a specific goal, but, at the same time, there exists the concept of "worldly" knowledge, the purpose of which is generally to affirm one's humanity. The purpose of communication and the exchange of ideas (including knowledge sharing) has a significant practical component, since it is a means of testing (and validating) one's own judgment. In particular, Borghi highlights the concept of 'volksaufklärung': the function of one's own enlightenment as a product or result of enlightenment of others. Hislop (2002) refers to the Nonaka/Takeuchi (1995) model by noting that within the knowledge creation process, tacit and explicit knowledge are "mutually constituted" in a system; to be truly useful, knowledge artifacts need to be both interpretable and actually interpreted. Moreover, 'knowledge' is an integrative process that is inseparable from activity.

\subsection{Drivers of knowledge sharing}

Based on these philosophical frameworks, there have been several recent discussions and case studies of what actually drives knowledge sharing. Focusing on an electronic network of practice, McLure, Wasko, and Faraj (2005) find that, in fact, an "expectation" of knowledge sharing can be built into a system, and will then influence behavior. In addition to specific conceptions of ownership, conceptions of "provenance" may also 
have a role; the reputation of the "originator" of a particular knowledge process or artifact will be enhanced if he or she is credited for it properly even if there is no opportunity for that individual to receive a direct financial reward. At the same time, they highlight the "intrinsic" motivation behind knowledge sharing. Something as simple as the statement that "it feels good to help other people" cannot be ignored. Another recent study, by Bock, Zmud, Kim, and Lee (2005), identifies three broad groups of factors that facilitate knowledge sharing. Specifically, these are related to individual benefits, group benefits, and organizational benefits. Knowledge sharing, they find, is affected positively by such issues as an anticipation of reciprocity, a direct relationship to self-image and self-worth, an organizational climate that places a premium on innovation and fairness, and, again, an actual expectation or sense that sharing is the "normal" way of interacting with knowledge. Without a context that actually calls for, demonstrates, encourages and facilitates knowledge sharing behaviors, though, these behaviors simply will not take place. Nor will there be a reason for them to occur. Yun and Allyn (2005) find that knowledge sharing behaviors can be related to individual needs and motives. In particular, the results of their empirical study support the hypothesis that when individuals have a direct moral or ideological investment in the success of the organization they are a part of, they will be more open to sharing knowledge. Exploring the social aspect of knowledge sharing, they validate the relationship between knowledge sharing and pro-social values (i.e., a concern for others' success and well-being). Their study's results are also able to support the (fairly logical) assertion that work coordination - that is, situations where the exchange of ideas is necessary for joint success - will be positively related to knowledge sharing. Interestingly, the authors do not back the hypothesis that knowledge sharing is driven by the desire to create and maintain a particular image or persona.

Another recent study, by Wang and Yang (2007), looks at individual personality determinants that either foster or hinder knowledge sharing. They argue that, particular traits of individuals positively affect knowledge sharing, with the implication that knowledge will be shared given a concentration of individuals with those traits. Specifically, they identify 'agreeableness' (the desire to support the success of colleagues), extraversion (knowledge sharing seen as a way of establishing a community, finding one's place in it, and making friends), and conscientiousness (where both the creation and the propagation/dissemination of knowledge are seen as an inherent part of a job whether or not they are listed in the actual job description). On an "enterprise-wide" level, Kharabsheh (2007) identifies a set of features that will likely foster knowledge sharing. He notes that a culture of trust in co-workers and management is particularly important, along with a proven high level of 'absorptive capacity' for recognizing new ideas and seeing their value, as well as an overall orientation towards ongoing learning and an organizational ethic of providing the best possible service to customers/clients using all available means.

Whether or not knowledge sharing can be fostered by specific rewards has been a topic of some debate. Hall and Graham (2004) list five broad categories of such rewards that should compensate for some of the obvious costs of knowledge sharing. These rewards can be obvious and explicit (e.g. specific economic bonuses, access to additional knowledge) or soft (as discussed above, related to reputation and self-satisfaction). In addition, knowledge sharing may call for particular allowances or infrastructures that actually make it possible. Of course technological components are one type, but so are social factors that treat every participant in an organization as a potential source of knowledge and that drive the establishment of communities within which knowledge can be shared without immediately "escaping" to the world at large. Interestingly, they also highlight the importance of boundary objects such as shared classification schemes and social spaces to facilitate or guide knowledge sharing. Milne (2001), on the other hand, 
argues that specific extrinsic rewards are actually not a good way of ensuring knowledge sharing. His argument is that by their definition, rewards are oriented towards the achievement of specific goals, regardless of methods or behaviors, while the positive effects of knowledge sharing may not be obvious immediately. Similarly, Bock and Kim (2002) find that rewards of knowledge sharing are often triggers for a single instance of knowledge sharing practices, but do not actually have an effect on subsequent cases or, for that matter, make the actual long-term benefits of knowledge sharing activities clear to participants. In fact, rewarding knowledge sharing - that is, setting up a competition essentially subverts the reasons why knowledge should be shared and puts a strong emphasis on just how unnatural and seemingly illogical an activity it is.

\section{Introducing an ethic of knowledge sharing}

In any case, so far, most of the writing that has looked at knowledge sharing critically has been limited to professional or formal settings, where the process is either mandated or expected to take place. The focus of these studies has overwhelmingly been on the specific conditions that affect knowledge sharing positively or negatively, rather than on attitudes regarding whether knowledge sharing should even take place, or the necessary preconditions for it. Similarly, there has been little written about the real or perceived goals of knowledge sharing. One of the points that Takeuchi and Nonaka make is particularly relevant here. "Knowledge, unlike information", they write, "is as much about ideals as it is about ideas." With this in mind, one question that it may be worth thinking about is the concept of an "ethic" of knowledge sharing - a set of mental models, behaviors and practices that would make knowledge sharing "natural" and expected, and thus change the entire conversation to give reasons for the sharing of knowledge, rather than finding reasons against the practice. And as suggested by the Grand Theft Auto IV example, some ideas for these ethics can be found in the practices of certain informal or non-formal communities.

\section{The three new ethics}

"What drives knowledge sharing in the absence of immediate, tangible rewards and group benefits" is the question that would underlie an alternative approach to knowledge sharing. Examples of where this type of knowledge sharing is taking place every day include the non-market "piracy" or unauthorized, non-commercial distribution of text, audio, video and software, primarily via the Internet. Examining these practices suggests that over the last twenty or so years, at least three (and possibly many more) "alternative ethics" of knowledge sharing have developed, distinguished from each other by drastically new relationships between information/knowledge and their producers and consumers. These three ethics can be termed the "hacker ethic", the "participatory culture ethic", and the "proselytization commons ethic."

\subsection{The hacker ethic}

Whatever its image in the popular culture, the hacker movement is based around a set of fairly well-defined principles that can be seen as being closely related to the academic discussion on knowledge sharing. Barlow (1994) identifies the two main tenets of the hacker ethic as the idea that "information has to move" and the belief that "information wants to be free." To this, he adds a third feature: an understanding of "the inexplicable 
pleasures of information itself, the joys of learning, knowing, and teaching; the strange good feeling of information coming into and out of oneself." Crystal (2001) adds the notion that information has value, but that the value of information increases or compounds as it is transformed and shared. Another underlying belief of this ethic is that knowledge is neither created nor destroyed, but merely accessed. "Nobody should ever have to solve a problem twice," he writes. The hacker views the world as a series of problems waiting to be solved; it does not particularly matter by whom. Capurro (2005) brings in the possibility of engagement with information in a combination of work and joy, of "Sunday and Friday."

Thought of in terms of its relationship to, and conceptualization of, information as an object, some of the implications of the hacker ethic are actually quite close to what Schultze and Leidner find is the dominant metaphor of viewing knowledge in normative discourse. The key difference, though, is that while much of the literature they survey limits itself to the question of how knowledge should be accessed and transferred, the key question of the hacker ethic is meant to answer is why it should be. Information processed as knowledge is a common resource, the full benefits of which are only released once it is accessed. Here, a mention of Lawrence Lessig's idea (2001) of the "creative commons" that both respects copyright but also calls on copyright holders to acknowledge the value of broad public access to works is particularly appropriate. Rather than existing to serve the user, knowledge is almost a living entity in and of itself, though it depends on the user in a mutually beneficial relationship. Whether or not "sharing" is unnatural under the hacker ethic, hoarding information and knowledge certainly is, especially since most likely, they will either escape in the end, or will be accessed by another user in a process that will be necessarily inefficient. If knowledge is neither created nor owned, knowledge sharing becomes an activity that should be acceptable and accepted. Yet another implication of the hacker ethic is that the effects of released knowledge may not be immediate or immediately obvious, but they will reveal themselves. With its focus on the individual as a conduit for - rather than the 'creator' or 'master' of information/knowledge, this ethic also re-emphasizes the idea that the human participants in the knowledge sharing process are themselves allowances for it. Just as Wang and Yang find that some individuals are more suited to sharing information than others, the hacker ethic prioritizes the role and responsibility of the individual information user in accessing and interpreting information and unlocking knowledge. No matter what technologies may be present to facilitate the process, if there is no desire to actually start it, there is no way it will actually start by itself. What the hacker ethic implies, then, is that participants in the knowledge process, those who gain access to knowledge, whether because of their own work or because they are given access, have a duty to share it, or to facilitate its transmission.

\subsection{The participatory culture ethic}

Henry Jenkins' $(1992,2006)$ concept of the "participatory culture" accepts the treatment of information products as commodities. Its emphasis is on redefinition and modification of existing knowledge to create new objects. His original analysis primarily deals with fanfiction - fan-written stories set in established popular culture "universes" that have the potential to unlock unintended or non-obvious meanings. Since then, this concept has also been applied to creations such as music videos that combine different video and audio tracks and mash-ups that bring together information from different online sources. Regardless of specific media, these works are forms of both expression and civic engagement. Knowledge sharing under a participatory culture ethic does not necessarily create knowledge, but it does create what is very close to art. The knowledge sharing 
communities he describes are characterized by strong support for creation and for sharing - in part, because the original materials these cultures are based on are themselves shared or borrowed. These communities are also frequently based around informal mentorship structures and a strong consensus that members' contributions matter to the maintenance of the community. There is also some degree of social connectedness between members, frequently defined as either positive ("we are members of this community") or negative ("we are members of this community explicitly because we are not/do not want to be/are excluded from being members of some other one").

Emphasis in the participatory culture ethic is on the creative abilities of the individual. Knowledge creation, it argues, is easier than one may think, and knowledge sharing directly benefits both the creator and the narrow, inter-invested group that he or she is a part of. This argument addresses one of the major obstacles to knowledge sharing that other scholars have identified: the fear that by sharing knowledge, one will be engaging in an activity that has a high opportunity cost and takes the creator out of competition with members of his or her peer group. At the same time, by treating the product of knowledge sharing as a commodity that exists alongside the original, neither better nor worse, but different, it implies that to share knowledge is not to give up ownership, but, to create something new. In addition, in this ethic, what drives knowledge sharing is the desire to spread a particular commodity and to strengthen the social group that is defined by accessing and interacting with it. The participatory culture ethic is also non-technological and independent of specific settings: its focus is on the process of knowledge sharing, not on the mode of transmission. In a way, this actually puts this ethic quite close to traditions of oral and written folklore conceptualized as a pretechnological form of knowledge sharing. Another important consideration is that participatory culture is tied very strongly to the concept and action of storytelling modifying existing images or details to a new use and to new meanings while retaining the original. It is both altruistic and concerned with creation as an act that is pleasurable. A strong gift-giving component may not be stated, but it is implied.

\subsection{The proselytization commons ethic}

The idea of the "proselytization commons" (Leonard, 2005a, 2005b) is inherently ideological. It revolves around knowledge (in the form of media and ideas) that is shared in particular real or virtual spaces not only due to specific affordances, but in advancement of specific goals. Its particular characteristic is not as much a belief in the exclusive ownership of knowledge as the trust that some particular type of knowledge is itself "important" to the point of being worth giving away, and once given away, promotes certain behaviors, practices and world-views; it is the essentially religious desire to expand the group of those that share in a particular knowledge. The case of the Grand Theft Auto IV videogame mentioned earlier is a typical example - and odd as it may be, serves as a good illustration of how the volksaufklärung concept is being adapted in the age of the Internet and peer-to-peer distribution. Another idea that underlies the proselytization commons is that shared knowledge both defines the group and validates individual participants by tasking them with spreading it. Belonging to the group becomes an active choice - as much task as lifestyle. In fact, recent empirical studies such as that of Lee, et al. (2006) find that cooperation and knowledge sharing in an online setting is positively affected when participants feel that they are in the same in-group that has a particular agenda. If in the hacker ethic, the role of the community is minimized and the participatory culture ethic rests on closed, self-sustaining communities, the proselytization commons is based on a community that is focused outward, towards 
expansion and growth that can only be achieved by self-promotion. In this ethic, the specific individual benefits of knowledge sharing are simply not considered as important as the benefit to the community, or the expectation is that the individual will benefit from the expansion and empowerment of the community that he or she is a part of. Of course, what this ethic calls for in order to be successful is a shared set of beliefs in the goals of the community and a shared set of benefits that the community's continuing success will bring to its individual members.

\section{Conclusion}

Imagining these knowledge sharing practices and ethics is one thing, but thinking about how they can be made to apply to the professional world is another entirely. Nonetheless, it is certainly possible, as can be seen by the emergence of concepts like viral marketing that depend on this kind of unregulated, undirected knowledge sharing. The open-source software movement is another obvious example, and interestingly, none of the three ethics described are much concerned with the free-riding issues that are often brought up when talking about knowledge sharing in formal environments. But why would they be? The hacker ethic is clearly altruistic, and calls on the individual participant to devote skills, time and energy in advancement of a broad and non-ideological cause. Participatory cultures are not expected to benefit the uninterested. And the proselytization commons is targeted knowledge sharing with a purpose; its goal is to attract and engage the possible free-rider.

The more important issue to deal with is whether all three of these can be created in particular settings, or whether they have to arise naturally. Since at least several of the studies mentioned, such as Bock's, and Yun and Allyn's, do specifically note that environments play a major role in driving knowledge sharing, it may be argued that if the proper ingredients and support mechanisms are in place, knowledge sharing driven by one of these ethics may occur. Thus, for a hacker ethic-like effect, an organization would have to consistently emphasize the value of discovery and the idea that there are plenty of processes waiting to be discovered or uncovered. The effect of the participatory culture ethic could be achieved by a sense of continuous playful improvement and reimagining, a "perpetual beta" that opens all current practices for modification in unexpected but potentially transformative ways. One obvious example of this kind of approach is the Google Maps project, which has been upgraded both internally, adding new functionalities to what was a fairly standard online street atlas, and externally, via third party applications that use the core product but add extra value to it. The proselytization commons approach would be utilized in a case where an organization believes strongly in its mission and in the ability and power of every individual within the organization to contribute to it.

The social, economic and even political importance of emerging knowledge sharing structures that are driven by some of these ethics, such as Wikipedia, is hard to deny. Over the last several years, these have already made significant impacts on a wide range of areas that have previously been defined by limited, controlled and mediated access to information and knowledge. From initial reluctance, scholars (Fallis, 2008; Lim, 2009.) are now acknowledging their potential and real benefits. This, in turn, makes understanding when and why knowledge sharing is successful, and when and why it is not more important than ever before. Two approaches to sharing knowledge that are significantly different from each other are now frequently in open competition. Successfully navigating between them will involve evaluating the strengths and weaknesses of both. Thus, this paper largely outlines the shortcomings of formal, directed 
knowledge sharing while introducing many of the strengths of knowledge sharing of the informal and subversive kind. But that has its own issues. Is knowledge itself a luxury good or a staple: does the unique possession of knowledge impose a measure of prestige and power on whoever possesses it that is more advantageous than whatever could be gained by sharing? In environments that are competitive by nature, that thrive on competition and conflict, can non-competitive knowledge sharing ever take place? And perhaps most troubling is the possibility that these alternative approaches to knowledge sharing can only exist as acts of resistance to dominant paradigms and to cultures that are based on systems of sharing in some cases and hoarding or restricting access in others. If knowledge sharing is prioritized, for example, how can one justify restrictions and highly negative attitudes to a case of a group of students working on a take-home assignment together? In any case, it is clear that while new technologies are giving the issue of knowledge sharing particular relevance, the answers to many of the emerging problems in knowledge sharing must be organizational. Technology remains the tool, not the process or driver, and relying on technology to actually lead to knowledge sharing will result in nothing but a lot of expensive, abandoned technology.

\section{Acknowledgements}

This article is based on work originally prepared for Dr. Ronald E. Day's Philosophy and Critical Theory of Information seminar at the School of Information and Library Science, Indiana University, Bloomington, USA. The author wishes to thank Dr. Day and the other students in the seminar for their thoughtful comments and suggestions, the editors of this journal and the anonymous reviewers for their guidance and hard work in preparing this article for publication.

\section{References}

1. Augier, M., Shariq, S., \& Vendelo, M. T. (2001). Understanding context: Its emergence, transformation and role in tacit knowledge sharing. Journal of Knowledge Management, 5(2), 125-136.

2. Barlow, J. P. (1994). The economy of ideas. Wired, 2(3), 84-90, 126-129.

3. Barrett, S., \& Konsynski, B. (1982). Inter-organizational information sharing systems. MIS Quarterly, 6(4), 93-105.

4. Bartol, K., \& Srivastava, A. (2002). Encouraging knowledge sharing: The role of organizational reward systems. Journal of Leadership \& Organizational Studies, 9(1), 64-76.

5. Bock, G. W., \& Kim, Y. G. (2002). Breaking the myths of rewards: An exploratory study of attitudes about knowledge sharing. Information Resources Management Journal, 15(2), 14-22.

6. Bock, G. W., Zmud, R., Kim, Y. G., \& Lee, J. (2005). Behavioral intention formation in knowledge sharing: Examining the roles of extrinsic motivators, socialpsychological forces, and organizational climate. MIS Quarterly, 29(1), 87-111.

7. Cabrera, A., \& Cabrera, E. (2002). Knowledge sharing dilemmas. Organization Studies, 23(5), 687-710. 
8. Capurro, R. (2005). Passions of the Internet. In W. Palaver \& P. Steinmair-Posel (Eds.), Passions in economy, politics, and the media in discussion with Christian theology (pp. 331-345). Vienna: Lit Verlag.

9. Chua, A. (2003). Knowledge sharing: A game people play. ASLIB Proceedings, 55(3), 117-129.

10. Churchman, C. W. (1971). The design of inquiring systems: Basic concepts of systems and organizations. New York: Basic Books.

11. Crystal, D. (2001). Language and the Internet. Cambridge: Cambridge University Press.

12. Currie, G., \& Kerrin, M. (2004). The limits of a technological fix to knowledge management: Epistemological, political and cultural issues in the case of intranet implementation. Management Learning, 35(1), 9-24.

13. Davenport, T. (1996). Some principles of knowledge management. Strategy+Business, 1(2), 34-40.

14. Davenport, T., De Long, D., \& Beers, M. (1998). Successful knowledge management projects. Sloan Management Review, 39(2), 43-57.

15. Economides, A. (2008). Culture-aware collaborative learning. Multicultural Education \& Technology Journal, 2(4), 243-267.

16. Fallis, D. (2008). Toward an epistemology of Wikipedia. Journal of the American Society for Information Science \& Technology, 59(10), 1662-1674.

17. Hall, H., \& Graham, D. (2004). Creation and recreation: Motivating collaboration to generate knowledge capital in online communities. International Journal of Information Management, 24(3), 235-247.

18. Hart, D. (2002). Ownership as an issue in data and information sharing: A philosophically based view. AJIS: Australian Journal of Information Systems, 10(1), 23-29.

19. Helmstadter, E. (2003). The institutional economics of knowledge sharing: Basic issues. In E. Helmstadter (Ed.), The economics of knowledge sharing: A new institutional approach. (pp. 11-38). Cheltenham, UK: Edward Elgar Publishing.

20. Hislop, D. (2002). Mission impossible? Communicating and sharing knowledge via information technology. Journal of Information Technology, 17(3), 167-177.

21. Ives, W., Torrey, B., \& Gordon, C. (2000). Knowledge sharing is a human behavior. In D. Morrey, M. Maybury, \& B. Thuraisingham (Eds.), Knowledge management: Classic and contemporary works (pp. 99-132). Cambridge: MIT Press.

22. Jenkins, H. (2006). Confronting the challenges of participatory culture: Media education for the 21st Century. Chicago: The MacArthur Foundation.

23. Jenkins, H. (1992). Textual poachers: Television fans and participatory culture. New York: Routledge.

24. Kankanhalli, A., Tan, B., \& Kwok-Kee, W. (2005). Contributing knowledge to electronic knowledge repositories: An empirical investigation. MIS Quarterly, 29(1), 113-143. 
25. Kharabsheh, R.Y. (2007). A model of antecedents to knowledge sharing. Electronic Journal of Knowledge Management, 5(4), 419-426.

26. Lee, M., Cheung, C., Lim, K., \& Sia, C. (2006). Understanding customer knowledge sharing in web-based discussion boards: An exploratory study. Internet Culture, 16(3), 289-303.

27. Leonard, S. (2005a). Progress against the law: Anime and fandom, with the key to the globalization of culture. International Journal of Cultural Studies, 8(3), 281-305.

28. Leonard, S. (2005b). Celebrating two decades of unlawful progress: Fan distribution, proselytization commons, and the explosive growth of Japanese animation. UCLA Entertainment Law Review, 12(2), 189-265.

29. Lessig, L. (2001). The future of ideas: The fate of the commons in a connected world. New York: Random House.

30. Lim, S. (2009). How and why do college students use Wikipedia? Journal of the American Society for Information Science and Technology, 60(11), 2189-2202.

31. McLure Wasko, M., \& Faraj, S. (2005). Why should I share? Examining social capital and knowledge contribution in electronic networks of practice. MIS Quarterly, 29(1), 35-57.

32. Milne, P. (2001). Rewards, recognition and knowledge sharing: Seeking a causal link. Australian Academic and Research Libraries, 32(4), 321-331.

33. Olaniran, B. (2009). Discerning culture in e-learning and in the global workplaces. Knowledge Management \& E-Learning: An International Journal, 1(3), 180-195.

34. Riege, A. (2005). Three-dozen knowledge sharing barriers managers must consider. Journal of Knowledge Management, 9(3), 18-35.

35. Rioux, K. (2005). Information Acquiring-and-Sharing. In S. Erdelez, K. Fisher, \& L. McKechnie (Eds.), Theories of information behavior (pp. 169-173). Medford, NJ: Information Today.

36. Savolainen, R. (2006). Information use as gap-bridging: The viewpoint of sensemaking methodology. Journal of the American Society for Information Science and Technology, 57(8), 1116-1125.

37. Schultze, U., \& Leidner, D. (2002). Studying knowledge management in information systems research: Discourses and theoretical assumptions. MIS Quarterly, 26(3), $213-242$.

38. Smoliar, S. (2007). The poetics of knowledge sharing: Putting Aristotle to work in the enterprise. International Journal of Innovation \& Learning, 4(1), 26-39.

39. Stoddart, L. (2001). Managing intranets to encourage knowledge sharing: Opportunities and constraints. Online Information Review, 25(1), 19-28.

40. Storey, J., \& Barnett, E. (2000). Knowledge management initiatives: Learning from failure. Journal of Knowledge Management, 4(2), 145-156.

41. Takeuchi, H., \& Nonaka, I. (1995). The knowledge creating company: How Japanese companies create the dynamics of innovation. New York: Oxford University Press. 
42. Take-Two Interactive Software, Inc. (2008, September). Reports record third quarter fiscal 2008 financial results. [Press release]. New York: Take-Two Interactive Software.

43. Wang, C. C., \& Yang, Y. J. (2007). Personality and intention to share knowledge: An empirical study of scientists in an R\&D laboratory. Social Behavior and Personality: An International Journal, 35(10), 1427-1436.

44. Xerox offers new knowledge sharing solutions. (1999). THE. Journal, 26(10), 16.

45. Yun, S., \& Allyn, M. (2005). Causes of knowledge sharing behaviors: Motivational/functional approach. Journal of the Academy of Business and Economics, 3(1), 88-92. 